\title{
Impact Factor: a crude yardstick which does not measure influence or impact on clinical practice
}

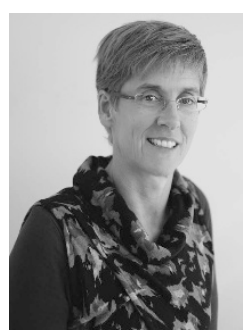

\author{
LA Harvey \\ Sydney, Australia \\ E-mail: spinalcord@iscos.org.uk
}

Spinal Cord is pleased to announce a 20\% increase in its Impact Factor to 1.87 with a 5-year Impact Factor of 2.112. This is good news for the journal, its readers, its authors, and its owner (the International Spinal Cord Society) because Impact Factor continues to be the yardstick by which journals are judged. A high Impact Factor provides an incentive for researchers to submit their work to a journal, and with increasing submissions journals can be more selective about what they publish. Researchers are cognisant of Impact Factor because it is used by universities and funders to judge research performance. Researchers with more publications in high Impact Factor journals may be more likely to be promoted and more likely to receive grants than researchers with publications in low Impact Factor journals. So Impact Factor drives decisions that researchers make about where to publish their work.

Much has been written about the problems of using Impact Factor to judge journals, papers and researchers, and there are strong movements to discourage the use of Impact Factor as a metric altogether. In fact, some universities and funders have taken the bold action to ignore Impact Factor when researchers apply for promotions or seek grants. ${ }^{1,2}$ They and others are increasingly using other measures to judge journals, researchers and their publications such as the number of downloads, cites within social media and the quality of the science.

Some of the criticisms about Impact Factor are obvious when you look at how Impact Factor are calculated:

$$
2016 \text { Impact Factor }=\frac{\text { Cites in } 2016 \text { to articles published in } 2014 \text { and } 2015}{\text { Total citable articles published in } 2014 \text { and } 2015}
$$

The reliance on citations to determine Impact Factor mean that Impact Factor does not necessarily reflect either the quality of the papers within a journal or how often papers are downloaded and read. Most importantly, Impact Factor does not measure a journal's influence and impact on clinical practice.

Journals seek to increase their Impact Factor by publishing papers that are likely to be highly cited and papers that cite prior publications from their own journals. Some of the most highly cited papers describe laboratory techniques or outcome measures. These papers are cited every time a researcher uses that technique or outcome measure. Similarly, review papers are often highly cited because they provide a convenient summary of a topic that researchers often use in the introductions and discussions of their own papers. The potential for review papers to be highly cited partly explains the burgeoning number of review papers published by journals; on some topics there are now more review papers than original research. This may be an unfortunate consequence of journals trying to increase their Impact Factors.

Of course widely cited papers are not necessarily widely read papers. Nor do they necessarily reflect wellconducted or innovative research. Similarly, there is not always a direct relationship between the number of citations and the amount of work that has gone into a paper. A complex clinical trial that takes five years to complete may not be heavily cited if the results are not what future researchers want to hear. It is unfortunate that the pursuit by journals for a high Impact Factor can drive decisions about the types of papers they accept and the type of studies researchers undertake.

Despite obvious problems with the Impact Factor, Spinal Cord is pleased that its Impact Factor has increased by such a large amount. It will continue to work on increasing its Impact Factor but not at the cost of compromising its vision to publish scientifically rigorous and relevant papers that will influence clinical practice. Spinal Cord is in a privileged position as the official journal of the International Spinal Cord Society (ISCoS). This gives it global reach and global impact, and ensures that all members of ISCoS have access to the journal. Its impact cannot be captured in a single number.

1 Time to remodel the journal impact factor. Nature 2016; 535: 466.

2 Callaway E. Beat it, impact factor! Publishing elite turns against controversial metric. Nature 2016; 535: $210-211$.

Spinal Cord (2017) 55, 799; doi:10.1038/sc.2017.101 